\title{
Unusually Low Arcuate Artery in a Kenyan Cadaver
}

\author{
Thomas Amuti, Kamau Njonjo, Innocent Ouko, Ibsen Ongidi, Julius Ogeng'o
}

School of Medicine, University of Nairobi

Correspondence to: Thomas Amuti, PO Box 30197-00100, Nairobi; email: tomamuti@gmail.com

\begin{abstract}
Summary
The arcuate artery is one of the two major branches of the dorsalis pedis artery that supply the dorsum of the foot including interdigital spaces. The artery's origin varies but in almost all cases it branches in the proximal third of the dorsum of the foot. During routine dissection of the right foot in a black Kenyan, we encountered a case where the artery was located and branched in the distal third of the dorsum of the foot, at the level of the metatarsophalangeal joint. This is much more distal than previously reported in prevailing literature. This artery did not give off any dorsal metatarsal arteries but gave the digital arteries directly. The dorsalis pedis artery,
\end{abstract}

\section{Introduction}

The arcuate artery (AA) is usually a branch of the dorsalis pedis artery (DPA) that arises anterior to the lateral tarsal artery in the proximal foot at the tarsometatarsal joint. It passes laterally along the bases of the lateral four metatarsals, deep in the tendon of the extensor digitorum brevis. At the lateral aspect of the foot, it anastomoses with the lateral tarsal artery to form an arterial loop. It gives off the second through fourth dorsal metatarsal arteries which course between the toes, and each divides into two dorsal digital branches for the adjacent toe $(1,2)$.

Knowledge of the anatomical pattern of the arcuate artery is important for several reasons. First, it is critical during harvesting and application of myocutaneous flaps on the dorsum of the foot. Second, the distal part of the foot may constitute donor material for reconstructing the hand $(3,4)$. Third, it minimizes inadvertent injury during diagnostic and interventional procedures (5). Fourth, it is an important component in the description and classification of the dorsalis pedis artery (6). Lastly, it is important for understanding the concept and application of "topographical" or angiosome-guided bypasses to foot ischemic wounds (7) and endovascular "wound directed" revascularization (8), for assessing and judging the anatomical distribution of angiosomes, and collateral circulation in macro- and microcirculation (9). Several variations involving origin, course and branching have lateral and medial tarsal arteries had normal course in this foot.

Keywords: Translational research; Dorsalis pedis artery; Integration; Arcuate artery

Ann Afr Surg. 2020; 17(1):45-47.

DOI: http://dx.doi.org/10.4314/aas.v17i1.12

Conflicts of Interest: None

Funding: None

(C) 2020 Author. This work is licensed under the Creative Commons Attribution 4.0 International License.

been reported (1,4,10-13). High origin has also been reported in several studies $(6,12,14,15)$. Low origin/ location, however, is seldom reported.

\section{Case report}

During routine dissection of the dorsalis pedis artery in a Kenyan cadaver, we encountered a right foot with an arcuate artery that branched from the dorsalis pedis at the metatarsophalangeal joint and then gave the 2nd, 3rd and 4th digital arteries directly (Figs. 1 and 2). In the same specimen, the 2nd dorsal metatarsal artery branched from the DPA directly. The 3rd and 4th dorsal metatarsals were not seen. In the left foot however, the AA branched from the DPA at the tarsometatarsal joint and passed beneath the extensor digitorum brevis where it gave out the $2 \mathrm{nd}$, $3 \mathrm{rd}$ and 4 th dorsal metatarsal arteries (Figs. 1 and 2).

The point of origin of this unusual AA was measured from the base of the first metatarsal bone. The points of origin of the digital arteries were measured from the bases of the 2nd, 3rd and 4th metatarsals respectively and tabulated. Both measurements used a vernier calliper (Table 1). Photographs were also taken with the help of a camera (Carl Zeiss, 12.1 megapixels). To compare themorphometric values of the results, average values of the same parameters were taken in specimen with the common course and branching of thedorsalis pedis artery. 


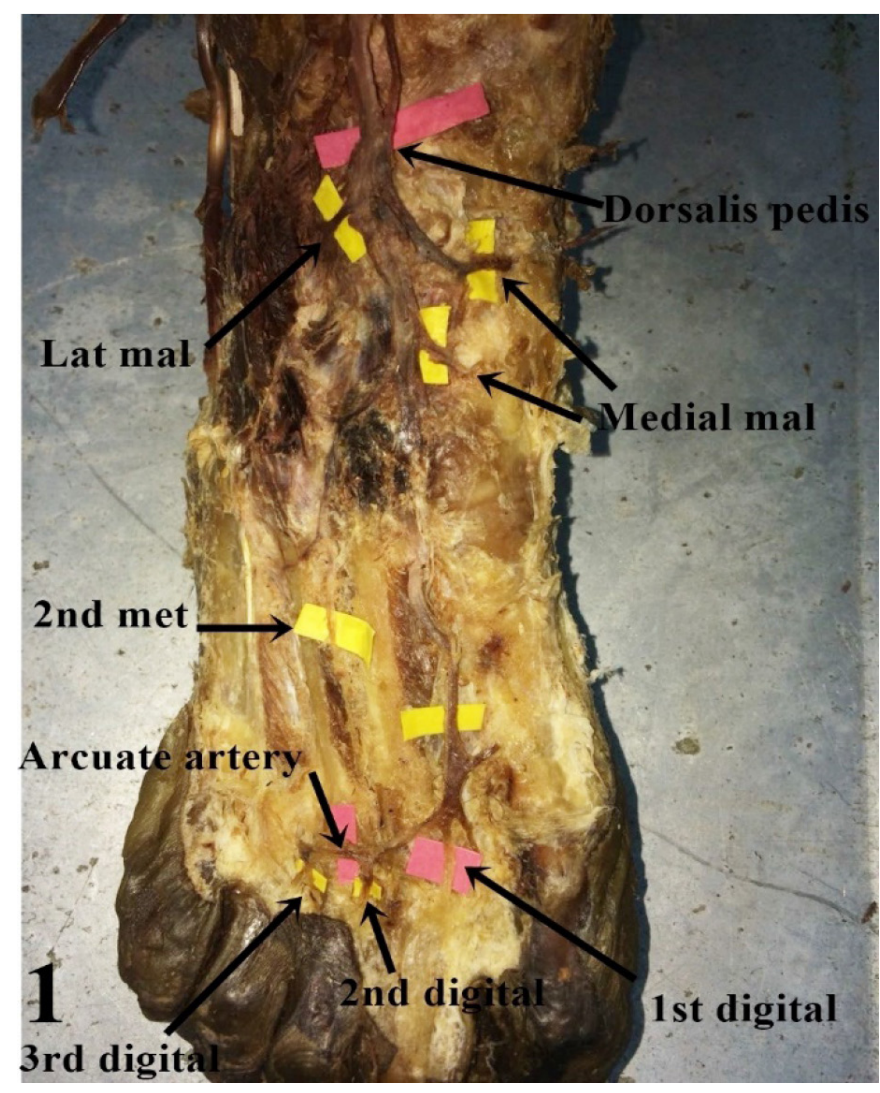

Figure 1. Variant low arcuate artery. The origin of this vessel is below the tarsometatarsal joint at the metatarsophalangeal joint. The vessels originating from it are digital arteries and not dorsal metatarsals.

\section{Discussion}

The pattern of arcuate artery observed is unique in two respects: first, the artery originated as a branch of the dorsalis pedis in the distal 3rd of the foot; second, the branching pattern varied with conventional descriptions. Data from the USA (16) reported that the DPA may originate at the cuneonavicular joint other than its common point of origin at the tarsometatarsal joint. In our results, the AA originated in the distal 3rd of the foot, $6.9 \mathrm{~cm}$ from the base of the $1 \mathrm{st}$ metatarsal bone. This was significantly lower than the average $2.7 \mathrm{~cm}$ that was recorded in Kenyan cadavers. Though literature has a few cases of the AA originating distal to the tarsometatarsal joint, none is from Africa. High origin arcuate artery has

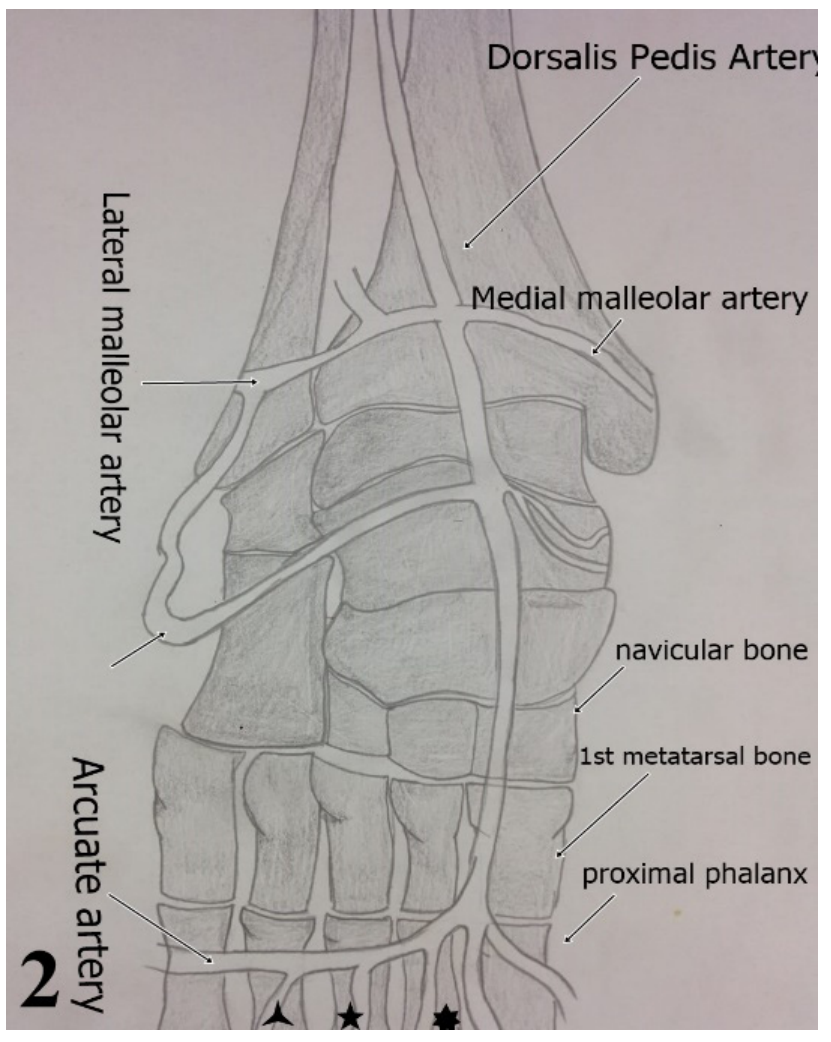

Figure 2. Representation of the distal arcuate artery. Note the 3rd digital artery (3-point star), the 2nd digital artery (5-point star) and 1st digital artery (6-point star). The other digital arteries cannot be seen from the diagram. The origin of this vessel is below the tarsometatarsal joint and is at the metatarsophalangeal joint. The vessels originating from it are digital arteries and not dorsal metatarsals.

however been reported in India (8).

The lateral and medial malleolar arteries were also noted to originate lower $(4.1 \mathrm{~cm}, 3.63 \mathrm{~cm}$ respectively from the base of 2 nd metatarsal bone) than the average results recorded from the same setting $(3.5 \mathrm{~cm}, 3.54 \mathrm{~cm}$ respectively from the base of the 2 nd metatarsal bone).

Regarding its branching pattern, the arcuate artery usually gives off the $2 \mathrm{nd}$, 3rd and 4th dorsal metatarsal arteries. In other instances, it may give the 2 nd and $3 \mathrm{rd}$ dorsal metatarsal arteries only, or the 2 nd metatarsal artery solely. In cases where it does not give any of the metatarsal arteries, these vessels have been shown to originate from the lateral tarsal artery (17). Of interest,

Table 1. Different points of origin of the branches of the dorsalis pedis artery

\begin{tabular}{|c|c|c|c|c|}
\hline $\begin{array}{l}\text { Variable } \\
\text { (measurements in } \\
\mathrm{mm} \text { ) }\end{array}$ & $\begin{array}{l}\text { Origin of the lateral } \\
\text { malleolar artery as } \\
\text { measured from the } \\
\text { base of the 2nd } \\
\text { metatarsal bone }\end{array}$ & $\begin{array}{l}\text { Origin of the medial } \\
\text { malleolar artery } \\
\text { as measured from } \\
\text { the base of the } 1 \mathrm{st} \\
\text { metatarsal bone }\end{array}$ & $\begin{array}{l}\text { Origin of the arcuate } \\
\text { artery as measured } \\
\text { from the base of the } \\
\text { 1st metatarsal bone }\end{array}$ & $\begin{array}{l}\text { Origin of the digital } \\
\text { arteries as measured } \\
\text { from the respective } \\
\text { bases of the } \\
\text { metatarsal bones }\end{array}$ \\
\hline Value (of variation) & 4.12 & 3.63 & 6.92 & $\begin{array}{l}\text { 2nd }-6.98 \\
\text { 3rd }-6.74 \\
4 \text { th }-6.66\end{array}$ \\
\hline Average values & 3.54 & 3.38 & 2.69 & - \\
\hline
\end{tabular}


in the Indian population where a high origin arcuate artery was noted, the dorsalis pedis artery continued as the anterior tibial artery, which divided into medial and lateral branches. The medial branch continued as the 1st dorsal metatarsal artery supplying the 1st intermetatarsal space while the lateral branch behaved like an arcuate artery giving off the $2 \mathrm{nd}$, 3rd and 4th dorsal metatarsal arteries (8). In our case however, the arcuate artery did not give out the dorsal metatarsal arteries but instead gave out the digital arteries directly. Unfortunately, there is paucity of data from previous literature for comparison.

It is plausible that the individual whose body was dissected was at risk of ischemia of the 2 nd to the 4 th toes following kinking of the dorsal digital arteries. This is because the vessels were given off at a joint-the metatarsal phalangeal joint. In our case, though, owing to lack of clinical information on the individual, it is difficult to confirm this.

The case observed occurred probably owing to genetic factors that affected the embryology of the vessel. Variant arterial anatomy of the foot is important for vascular surgeons during reconstruction as well as in flap selection from the DPA, AA or the dorsal metatarsal arteries. Though rare, this case is relevant and should be considered in procedures involving the DPA, the AA or its branches.

\section{Conclusion}

The arcuate artery may be located in the distal 3rd of the foot and have unusual branching pattern. Care should be taken during diagnostic and interventional procedures in the foot.

\section{References}

1. Alexandrescu VA, Triffaux F. Ischemic ulcer healing: Does appropriate flow reconstruction stand for all that we need? In: Wound healing-New insights into ancient challenges. INTECH Open Science/open minds 2018; 247-278.
2. Alexandrescu V, Hubermont G, Philips Y. Selective angioplasty following an angiosome model of reperfusion in the treatment of Wagner 1-4 diabetic foot lesions: Practice and multidisciplinary diabetic limb service. J Endovasc Ther. 2008; 15:580-593.

3. Attinger CE, Evans KK, Bulan E. Angiosomes of the foot and ankle and clinical implications for limb salvage: Reconstruction, incisions and revascularization. Plast Reconstr Surg. 2006; 117:261S-293S.

4. Chepte AP, Ambiye MV. Study of branching pattern of dorsalis pedis artery and its clinical significance. Anat Physiol. 2018; 8:3.

5. El-Saeed EM, El-Monisif AA, El-Sayed MA, et al. Anatomical study of dorsalis pedis artery and its surgical importance in reconstructive surgery. Alexandria J Med. 2008; 44:557-571.

6. Gabrielli C, Olave E. Origins of the dorsal metatarsal arteries in humans. Scand J Plast Reconstr Surg Hand Surg 2002; 36:221-225.

7. Huber JF. The arterial network supplying the dorsum of the foot. The Anatomical Record 1941; 80:373-391.

8. Kaur J, Chhabra U, Kaushal S. et al. High origin of arcuate artery-A case report. Indian J Surg. 2003; 75:23-24.

9. Luckrajh JS, Lazarus L, Naidoo N, et al. Anatomy of dorsalis pedis artery. Int J Morphol. 2018; 36:730-736.

10. Mitra NK, Habbal OA, El-Hag A, et al. Bilateral absence of the arcuate artery on the dorsum of the foot. Sultan Qaboos Univ Med J. 2007; 7:153-155.

11. Rajeshwari MS, Rushankumar BN, Vijayakumar. An anatomical study on dorsalis pedis artery. Int J Anat Res. 2013; 1:88-92.

12. Singh BN, Burmeister W, Machado K, et al. Variations of the origin of the arcuate artery. Am Pod Med Assoc. 2013; 103:181-184.

13. Sinnatamby CS. Last's anatomy. Regional and applied. 12th ed. Churchill Livingstone, Elsevier 2011. Chapter 3, Lower limb: 145-146.

14. Standring S. Gray's anatomy. The anatomical basis of clinical practice. 40th ed. Churchill Livingstone, Elsevier 2008. Section 9: 84:1455-1456.

15. Vasquez T, Rodriguez M-Niedenfuhr, Parkin I, Viejo F, Sanudo JR. Anatomic study of blood supply of the dorsum of the foot and ankle. Arthroscopy 2006; 22:287-290.

16. Vijayalakshmi S, Raghunath G, Shenoy V. Anatomical study of dorsalis pedis artery and its clinical correlations. J Clin Diag Res. 2011; 1:287-290.

17. Yamada T, Gloviczk P, Bower TC, et al. Variations of the arterial anatomy of the foot. Am J Surg. 1993; 166:130-135. 